\title{
Acute myocardial infarction in infancy: unmasking of anomalous origin of the left coronary artery from the pulmonary artery by ligation of an arterial duct
}

\author{
NARAYANSWAMI SREERAM, STEWART HUNTER, CHRISTOPHER WREN \\ From the Department of Paediatric Cardiology, Freeman Hospital, Newcastle upon Tyne
}

SUMMARY Myocardial infarction and left ventricular failure developed within hours of ligation of a large arterial duct in a four week old infant. Anomalous origin of the left coronary artery from the pulmonary artery was confirmed by echocardiography. Despite emergency translocation of the anomalous coronary artery the patient died.

Anomalous origin of the left coronary artery from the pulmonary artery is a rare cause of heart failure in infancy. It is usually an isolated abnormality, although association with a persistent arterial duct has been reported. ${ }^{12}$ We describe an infant who developed acute left ventricular failure within hours of ligation of a large duct.

\section{Case report}

A four week old female infant was admitted with a history of poor feeding. She had been delivered at 35 weeks' gestation (birth weight $2 \mathrm{~kg}$ ) by caesarean section because of maternal pre-eclampsia and she had been well until 48 hours before admission.

On admission she had the classic signs of a large arterial duct with cardiac failure. The chest $x$ ray showed cardiomegaly and pulmonary plethora. The electrocardiogram showed sinus rhythm, with ST segment depression in leads V2-V6 (fig). Cross sectional echocardiography confirmed a large duct and showed left atrial enlargement.

Because there was no improvement with medical treatment, the duct was ligated. The patient was extubated four hours after the operation but appeared unwell with tachypnoea and tachycardia and required re-intubation. A repeat chest $x$ ray showed persisting cardiomegaly and pulmonary ven-

Requests for reprints to Dr Narayanswami Sreeram, Department of Paediatric Cardiology, Freeman Hospital, Newcastle upon Tyne NE7 7DN. ous congestion. Cross sectional and colour Doppler echocardiography showed a slightly dilated, dyskinetic left ventricle, with mitral valve regurgitation. The patient was treated with infusions of dobutamine and glyceryl trinitrate.

Repeat cross sectional and colour Doppler echocardiography after $\mathbf{4 8}$ hours showed deteriorating ventricular function, worse mitral regurgitation, and identified an anomalous origin of the left coronary artery from the left posterior aspect of the main pulmonary artery. An electrocardiogram showed deep $Q$ waves in leads $\mathbf{I}, a V L$, and V6 associated with ST segment elevation and $T$ wave inversion (fig). Emergency translocation of the left coronary artery was undertaken. Extensive infarction of the left ventricle was seen at operation. The origins of the circumflex and left anterior descending arteries were found to be separate but immediately adjacent and they were transferred from the pulmonary artery to the aorta. Cardiopulmonary bypass could not be discontinued because of left ventricular failure, and the patient died.

\section{Discussion}

Anomalous origin of the left coronary artery from the pulmonary artery is rare. Because it usually presents with myocardial infarction in infancy, electrocardiographic diagnosis is often straightforward although echocardiographic confirmation may be difficult. ${ }^{3}$ Prospective diagnosis, before myocardial infarction has occurred, is unlikely to be possible. 


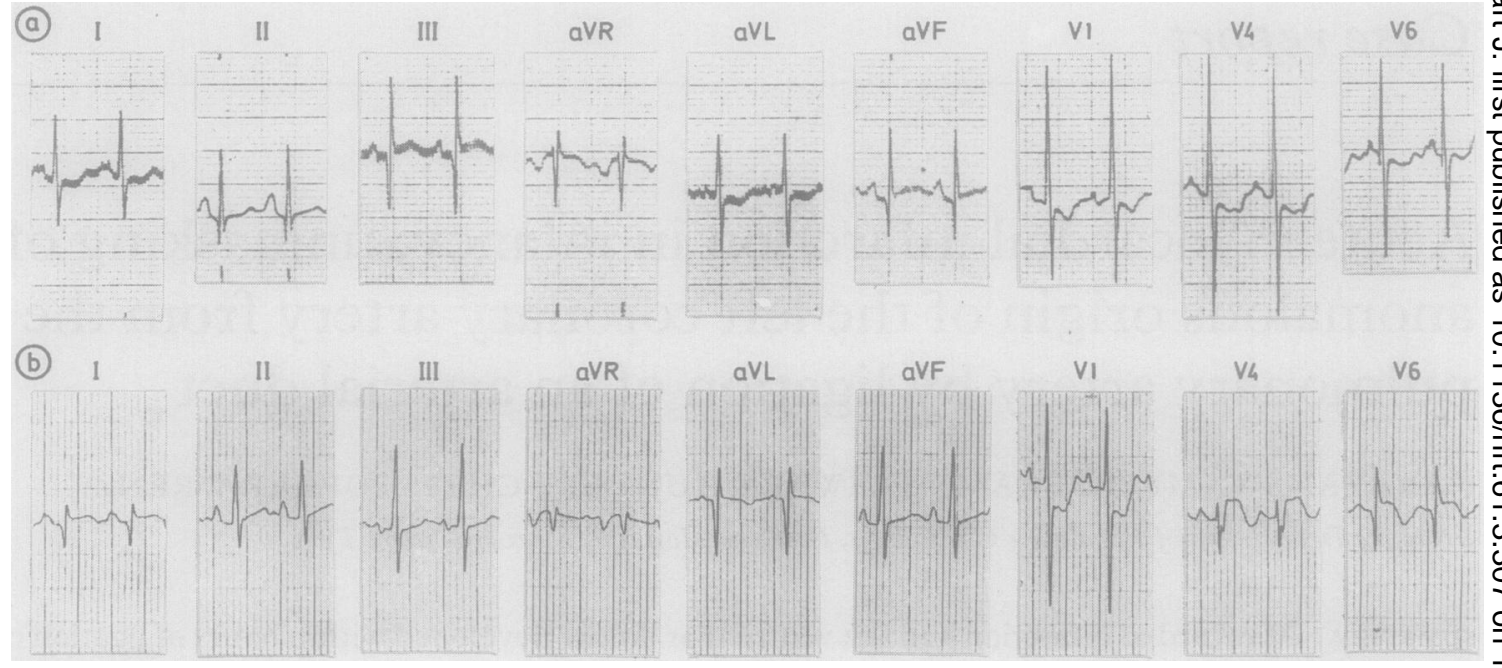

Fig (a) Preoperative electrocardiogram showing ST segment depression in anterolateral leads. (b) An electrocardiogram recorded 48 hours after operation showing acute transmural anterolateral infarction with new $Q$ waves in leads $I, a V L$, and $V 6$ and ST segment elevation in I, V4 and V6.

In the fetus and in the neonate with physiological pulmonary hypertension the perfusion pressure in the anomalous coronary artery is normal. As the pulmonary artery pressure falls after birth, left coronary perfusion is reduced, causing ischaemic myocardial damage that usually presents as congestive heart failure after two or three months. The age of onset of symptoms varies depending on the rate of fall of pulmonary artery pressure and the development of collateral connections with the right coronary artery. A large arterial duct will maintain adequate left coronary artery perfusion and thus delay presentation until the duct is ligated.

Ortiz et al reported a one year old child in whom cardiac failure developed two months after ligation of a large duct. ${ }^{1}$ Anomalous origin of the left coronary artery from the pulmonary artery was diagnosed two years later. Clinical deterioration may, however, be acute, as shown by the progression of events in our patient.

\section{References}

1 Ortiz E, de Leval M, Somerville J. Ductus arteriosus associated with an anomalous left coronary artery arising from the pulmonary artery: catastrophe after duct ligation. Br Heart $J$ 1986;55:415-7.

2 Vlodaver Z, Neufeld HN, Edwards JE. Coronary arterial variations in the normal heart and in congenital heart disease. New York: Academic Press, 1975:84.

3 Robinson PJ, Sullivan ID, Kumpeng V, Anderson RH, Macartney FJ. Anomalous origin of the left coronary artery from the pulmonary trunk. Potential for false negative diagnosis with cross sectional echocardiography. Br Heart J 1984;52:272-7.

\section{Notices}

\section{Coronary arteriography}

The 3rd International Symposium on Coronary Arteriography will take place in Rotterdam on 18 to 20 June 1989. Inquiries to Office for Post Graduate Medical Education, Erasmus University Rotterdam, PO Box 1738, 3000 DR Rotterdam, The Netherlands.

\section{British Cardiac Society}

The Annual General Meeting for 1989 will take place in Oxford on 6 and 7 April 1989, and the closing date for receipt of abstracts will be 6 January 1989 .

\section{Echocardiology}

The 8th Symposium on Echocardiography will take place in Rotterdam on 21 to 23 June 1989. Inquiries to Office for Post Graduate Medical Education, Erasmus University Rotterdam, PO Box 1738, 3000 DR Rotterdam, The Netherlands. 